\title{
AVALIAÇÃO QUÍMICA, PROTÉICA E BIODISPONIBILIDADE DE CÁLCIO NAS FOLHAS DE COUVE-MANTEIGA, COUVE-FLOR E ESPINAFRE
}

\section{ADRIANA CAMPOS BOAVENTURA}

Nutricionista

Orientador: Prof ${ }^{a}$. Dra. JOCELEM MASTRODI SALGADO

Dissertação apresentada à Escola Superior de Agricultura "Luiz de Queiroz", Universidade de São Paulo, para obtenção do título de Mestre em Ciências, Área de Concentração: Ciência e Tecnologia de Alimentos

PIRACICABA

Estado de São Paulo - Brasil

Janeiro - 1998 


\section{Dados Internacionais de Catalogaçāo na Publicaçāo (CIP) DIVISÃo DE BIBLIOTECA E DOCUMENTAÇÃo - Campus "Luiz de Quelroz"/USP}

Boaventura, Adriana Campos

Avaliação qulmlca, protéica e blodisponlbilldade de cálcio nas folhas de couvemanteiga, couve-flor e espinafre / Adriana Campos Boaventura. - P Piracicaba, 1998. $46 \mathrm{p}$.

Dissertação (mestrado) - E Escola Superior de Agricultura Luiz de Queiroz, 1998. Bibliografla.

1. Alimento vegetal 2. Análise protéica 3. Análise quimica 4. Biodisponibilidade 5. Cálcio 6. Folha 7. Nutrição humana 8 . Valor nutritivo I. Titulo 


\section{AVALIAÇÃO QUÍMICA, PROTÉICA E BIODISPONIBILIDADE DE CÁLCIO NAS FOLHAS DE COUVE-MANTEIGA, COUVE-FLOR E ESPINAFRE}

ADRIANA CAMPOS BOAVENTURA

Aprovada em: 31.03.1998

Comissão julgadora:

Prof ${ }^{\text {a. }} \mathrm{Dr}^{\mathrm{a}}$. Jocelem Mastrodi Salgado

ESALQ/USP

Prof ${ }^{\text {a. }}{ }^{\text {a. }}$ Marilia Oetterer ESALQ/USP

Prof ${ }^{\text {a. }} \mathrm{Dr}^{\mathrm{a} .}$ Maria Cristina Stolf Nogueira ESALQ/USP

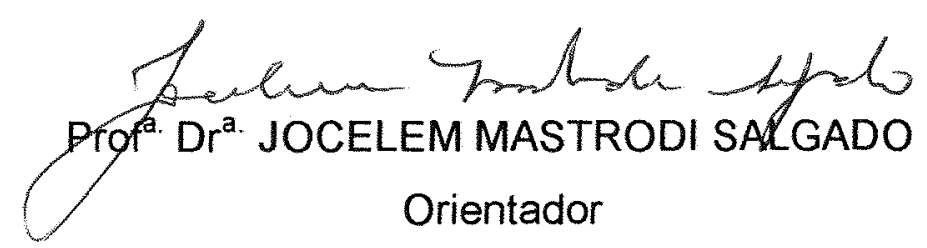


DEDICO

A meus filhos Daniela e Pedro a quem Deus me deu a oportunidade de recebe-los em minha vida.

\section{OFEREÇO}

A meus queridos pais Elias e Miriam e meu irmão Rodrigo pelo amor, carinho e amparo. 


\section{AGRADECIMENTOS}

À professora $\mathrm{Dr}^{\mathrm{a}}$. Jocelem Mastrodi Salgado, pela orientação e carinho prestado no transcorrer do trabalho;

À Fundação Coordenação e Aperfeiçoamento de Pessoal de Nível Superior (CAPES), pelo apoio financeiro, sem o qual seria impossível a realização deste trabalho;

À professora $\mathrm{Dr}^{\mathrm{a}}$. Solange Guidolin Canniatti-Brazaca do Departamento de Economia Doméstica, ESALQ/USP, pelo apoio prestado;

À técnica de laboratório Maria de Lurdes Perim Storer, da ESALQ/USP, pela amizade e total colaboração;

À Raquel Iracema da Silva, secretária do Setor de Nutrição Humana e Alimentos, pela amizade e carinho;

Ao professor Dr. José Eduardo Corrente, a Prof ${ }^{\mathrm{a}}$. Dra . Sonia Maria de Estefano Piedade e Luciane Brajão do Departamento de Matemática e Estatística, da ESALQ/USP, pela assessoria na análise estatística; 
Às funcionárias da Biblioteca do Departamento de Ciência e Tecnologia Agroindústrial, Beatriz Helena Giongo pelo auxílio na organização das referências bibliográficas e Midian Gustinelli pelo atendimento prestado;

Á Escola Canarinho e Creche da UNIMEP pelo carinho e cuidados prestados aos meus filhos;

Ao professor Victor Hugo V. Tejerina, pela amizade e incentivo;

Às minhas colegas de trabalho da UNIMEP, pelo apoio e incentivo;

Às minhas colegas do curso Neide, Gloria, Denise e Rita pela amizade e apoio durante o transcorrer do curso;

Aos amigos e amigas pelo carinho, solidariedade e incentivo nos momentos de alegria e dificuldade

Muito Obrigada 


\section{SUMÁRIO}

Página

LISTA DE FIGURAS....................................................... vii

LISTA DE TABELAS ..................................................... viii

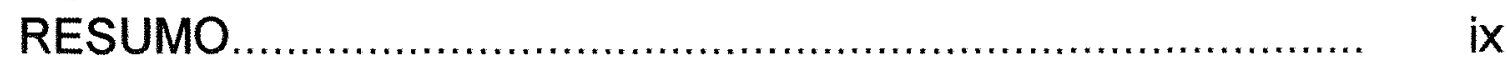

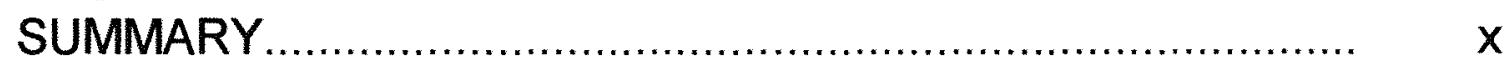

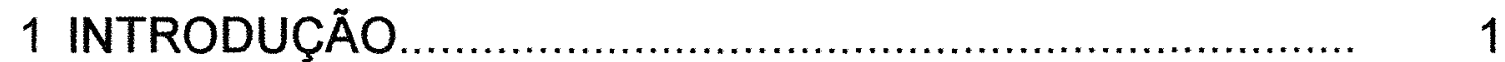

2 REVISÃO DE LITERATURA ............................................. 5

3 MATERIAL E MÉTODOS ............................................... 17

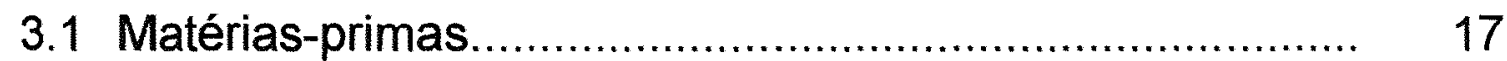

3.2 Preparo dos ingredientes.............................................. 17

3.3 Ensaio biológico para avaliação protéica........................... 18

3.3.1 Preparo das dietas.................................................. 18

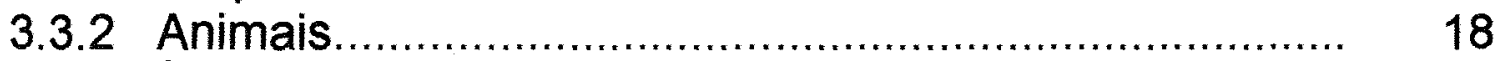

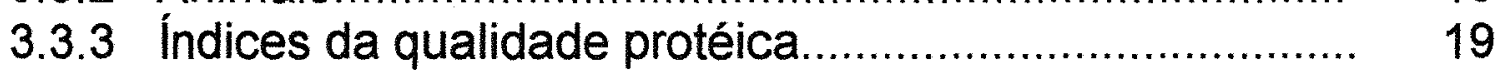

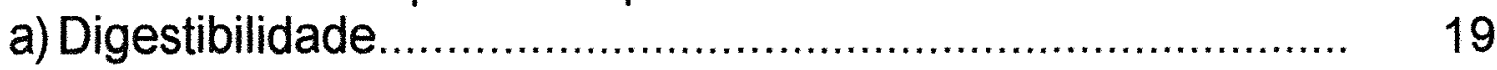

b) Utilização protéica líquida................................................ 20

c) Valor biológico............................................................ 20

d) Coeficiente de eficiência protéica........................................ 20

e) Coeficiente de eficiência alimentar................................... 21

3.4 Ensaio biológico de biodisponibilidade de cálcio............... 21

3.4.1 Preparo das dietas................................................ 21

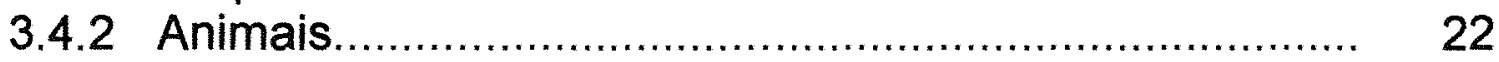

3.4.3 Análises químicas................................................. 24

3.4.4 Análise estatística................................................... 25

4 RESULTADOS E DISCUSSÃO....................................... 26

4.1 Parâmetros químicos..................................................... 26

4.1.1 Composição centesimal.............................................. 26

4.1.2 Digestibilidade "in vitro"........................................... 28

4.2 Ensaio biológico para avaliação protéica......................... 30

4.2.1 Parâmetros nutricionais............................................ 30

4.3 Fatores antinutricionais................................................. 31

4.4 Biodisponibilidade de cálcio........................................... 33

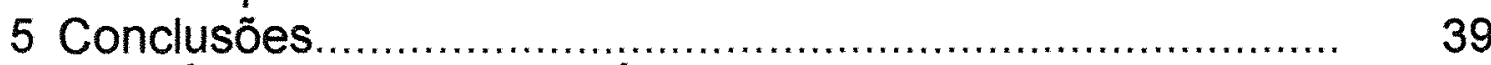

REFERÊNCIAS BIBLIOGRÁFICAS .................................. 40 


\section{LISTA DE FIGURAS}

Página

1 Ácido fítico $(\mathrm{mg} / \mathrm{g})$ e ácido oxálico (\%) nas farinhas de folhas de couve-manteiga, couve-flor e espinafre

2 Cálcio retido no fêmur (CRF) e a biodisponibilidade de cálcio (BIO) nas folhas de couve-manteiga e couveflor.

3 Consumo de ácido fítico (CAF) e ácido oxálico (CAO) nas farinhas de folhas de couve-manteiga, couve-

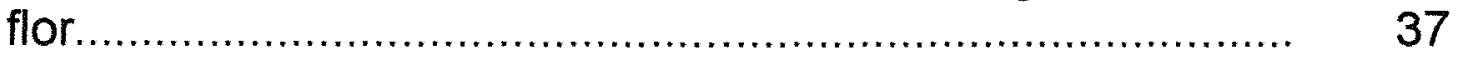

4 Retenção de cálcio (RC) e consumo de cálcio da dieta (CAD) nas farinhas de folhas de couve-manteiga, couveflor. 


\section{LISTA DE TABELAS}

Página

1 Composição centesimal $(\mathrm{g} / 100 \mathrm{~g})$ das folhas desidratadas de couve-manteiga, couve-flor e espinafre

2 Digestibilidade "in vitro" nas farinhas das folhas de couvemanteiga, couve-flor e espinafre

3 Ganho de peso, consumo de ração, coeficiente de eficiência alimentar (CEA), coeficiente de eficiência protéica (PER), digestibilidade (D), utilização protéica líquida (NPU) e valor biológico (VB), obtidos para dietas experimentais e controle.

4 Ácido fítico (mg/g amostra) e ácido oxálico (\%) nas farinhas de folhas de couve-manteiga, couve-flor e espinafre.

5 Biodisponibilidade de cálcio na folha de couvemanteiga.

6 Biodisponibilidade de cálcio na folha de couveflor.

7 Biodisponibilidade de cálcio na folha de couve-manteiga e couve-flor 


\title{
AVALIAÇÃo QUÍMICA, PROTÉICA E BIODISPONIBILIDADE DE CÁLCIO NAS FOLHAS DE COUVE-MANTEIGA, COUVE-FLOR E ESPINAFRE
}

\author{
Autora: ADRIANA CAMPOS BOAVENTURA \\ Orientador: Prof ${ }^{a}$. Dr ${ }^{a}$ JOCELEM MASTRODI SALGADO
}

\section{RESUMO}

O objetivo do trabalho foi avaliar através da análise química e protéica o valor nutricional das folhas de couve-manteiga, couve-flor e espinafre bem como a biodisponibilidade de cálcio nessas folhas. Verificou-se que a folha de couve-flor mostrou o melhor valor químico.

No ensaio biológico feito com ratos, a dieta de couvemanteiga, mostrou os melhores valores para os parâmetros nutricionais avaliados bem como a melhor retenção e biodisponibilidade de cálcio.

A dieta constituída com folha de espinafre provocou a morte, dos animais, provavelmente devido a presença de ácido oxálico e de outros fatores antinutricionais. 


\title{
CHEMICAL AND PROTEIC EVALUATION AND BIOAVAILABILITY OF CALCIUM ON COLE, CAULIFLOWER AND SPINACH LEAVES
}

\author{
Author: ADRIANA CAMPOS BOAVENTURA \\ Adviser: Prof ${ }^{a}$. Dr ${ }^{a}$. JOCELEM MASTRODI SALGADO
}

\section{SUMMARY}

The paper purpose was to check through chemical and protein analysis the nutritional value of cole, cauliflower and spinach leaves as well as calcium bioavailability in these leaves. It was found out that cole leaf has presented the best chemical value.

In the biological test made with rats, cole diet, has shown the best data for the evaluated nutritional parameters as well the best calcium retention and bioavailability.

The diet made up spinach leaf has brought death to test animals, probably due to oxalic acid presence and other nonnutritional factors. 


\section{INTRODUÇÃO}

A biodisponibilidade de cálcio é um assunto de interesse, uma vez que, a baixa ingestão crônica deste mineral está associada ao desenvolvimento da osteoporose, doença que afeta principalmente mulheres no período pré e pós menopausa, e homens em idade senil (Poneros \& Erdman Júnior, 1989). Esses autores, sugerem que a ingestão de alimentos que contém cálcio na forma biodisponível parece prevenir o aparecimento dessa doença. Afirmam que alguns alimentos contém altos níveis de cálcio, pouco se conhecendo porém, a respeito da biodisponibilidade desse mineral, principalmente nos alimentos de origem vegetal.

Os produtos de laticínios são as principais fontes de cálcio dietético, e a exclusão desses alimentos por indivíduos intolerantes à lactose, com dieta restrita em colesterol ou em regimes dietéticos pode resultar em ingestão marginal desse mineral.

Segundo Poneros \& Erdman Júnior (1988), é de grande importância a identificação de alimentos alternativos contendo significantes níveis de cálcio altamente biodisponíveis. 
As verduras folhosas como folha de couve-manteiga e couveflor fornecem quantidade significativa de cálcio, o mesmo acontece com o espinafre, porém a presença de ácido oxálico nessa folha impede, que o cálcio seja aproveitado (Coutinho, 1981).

A qualidade nutricional de um alimento depende basicamente de sua composição em nutrientes, da disponibilidade biológica destes nutrientes e da presença, dentre seus componentes, de substâncias tóxicas e/ou antinutricionais (Durigan, 1989).

A maioria das proteínas vegetais apresenta certos componentes indesejáveis que para maximizar a sua utilização devem ser removidos ou destruídos (Gupta \& Wagle, 1988).

Com uma necessidade global de expansão de proteinas alimentares, há um grande interesse sobre a presença de fatores antinutricionais em alimentos derivados de plantas (Graf, 1983).

Os minerais de cereais, leguminosas e outros alimentos de origem vegetal, em contraste, aos minerais de fontes animais, não são bem utilizados pelos homens e outros animais monogástricos (Erdman Júnior, 1981). Os fatores endógenos tem sido implicados como causadores da reduzida absorção de minerais provenientes de alimentos de origem vegetal. 
Dentre os fatores que influenciam na absorção do cálcio, destacam-se o ácido fítico e o ácido oxálico os quais podem formar compostos insolúveis, interferindo na absorção intestinal desse mineral (Mitchell et al., 1976).

O ácido oxálico, um ácido dicarboxílico, e seus sais são considerados como antinutricionais, eles podem tornar certos nutrientes minerais indisponiveis por ligarem-se a eles formando sais insolúveis que não são absorvidos no intestino (Vitakon, 1986).

O ácido fítico é um constituinte de muitos alimentos de origem vegetal, é um excelente quelante de íons minerais. Desde que o fitato não pode ser absorvido e os seres humanos tem limitada capacidade para hidrolisar a molécula de fitato, um efeito prejudicial do ácido fítico na biodisponibilidade de cálcio pode ser esperada (Lonnerdal, 1980).

No Brasil tem sido muito divulgado, a utilização indiscriminada de vários tipos de folhas na alimentação humana, como fonte alternativa, porém, muito pouco têm sido feito no sentido de verificar as conseqüências do consumo dessas folhas na saúde do indivíduo.

Com isso, um dos objetivos dessa pesquisa é verificar se determinadas plantas podem ser utilizadas na dieta humana, verificando os fatores que afetariam a saúde e o bem estar do indivíduo. Outro fator importante, é a identificação de fontes 
alternativas contendo níveis significantes de cálcio altamente biodisponível. Devido a esses fatores é que se propôs desenvolver esta pesquisa que têm por objetivos: verificar através das análises químicas e protéicas o valor nutricional das folhas de couvemanteiga, couve-flor e espinafre, e a biodisponibilidade de cálcio através de experimentos com animais, verificando o efeito dos níveis de ácido oxálico e ácido fítico na biodisponibilidade do cálcio. 


\section{REVISÃO BIBLIOGRÁFICA}

O crescente interesse pelo cálcio dietético é justificado pelas evidências científicas que o associam a doenças como osteoporose, hipertensão e câncer. Porém como as evidências são insuficientes, não se pode estabelecer que a dieta é o principal fator no desenvolvimento dessas doenças (Miller, 1989).

A osteoporose afeta 15 a 20 milhões de pessoas, incluindo uma em cada três com mais de 65 anos de idade, sendo oito vezes mais comum em mulheres do que em homens (Turner \& Whitney, 1989).

O preço físico deste distúrbio é mensurado em 1,3 milhões de fraturas por ano. Metade destas envolvem as vértebras, 200.000 são fraturas de quadris, que resultam em incapacidade, cuidados de enfermagem prolongados (National Center for Health Statistics, 1988). Estima-se que a proporção de americanos com mais de 65 anos de idade irá dobrar de $12 \%$ em 1988 para $24 \%$ em 2020, com isso em razão à alta probabilidade de todos os idosos serem afetados, o aumento da longevidade da população enfatiza a 
necessidade da prevenção precoce da osteoporose (Krause \& Mahan, 1994).

Dados implicando ingestões dietéticas inadequadas de cálcio no desenvolvimento da hipertensão, foram tirados de uma análise das informações envolvendo 10.000 pessoas com idade de 18 a 74 anos. Em uma comparação com ingestão de 17 nutrientes, com incidência de hipertensão, a mais alta correlação foi negativa para o cálcio (McCarron, 1984).

Quando o estado nutricional de cálcio do indivíduo é subótimo, este pode ser melhorado analisando-se os requerimentos para o cálcio e os fatores que afetam a sua absorção e utilização.

O cálcio é o mineral mais abundante no organismo. Constitui cerca de 1,5 a $2 \%$ do peso corpóreo e $39 \%$ dos minerais corpóreos. Cerca de $99 \%$ estão nos ossos e dentes. O restante, $1 \%$, está no sangue e fluídos extracelulares e dentro das células de tecidos moles, onde regula muitas funções metabólicas importantes (Krause \& Mahan, 1994).

O cálcio esquelético está distribuído em dois "pools": um lento, não permutável, que é estável e não acessível para a regulação a curto prazo na homeostase; e um rápido, permutável, utilizado em atividades metabólicas. Esse componente permutável pode ser considerado como reserva que é acumulada quando a dieta fornece 
uma ingestão adequada de cálcio. Ele é armazenado principalmente nas extremidades dos ossos longos em estruturas cristalinas conhecidas como trabéculas e pode ser mobilizado para fornecer maiores quantidades na gravidez, crescimento e lactação. Na falta dessa reserva, o cálcio deve ser retirado de substâncias mais estáveis do osso. Uma prolongada e inadequada ingestão de cálcio pode ocasionar uma estrutura óssea deficiente (Krause \& Mahan, 1994).

Existe uma constante absorção e reabsorção do osso. Em crianças, a deposição óssea, controlada pela atividade dos osteoblastos, células formadoras do osso, é maior que a reabsorção, controlada pelos osteoclastos. Por outro lado, as alterações ósseas freqüentemente observadas na idade avançada ocorrem quando a reabsorção predomina e há um decréscimo da quantidade absoluta do osso (osteoporose) Mitchell et al. (1991).

O processo predominante depende da idade e do estado fisiológico do indivíduo. A síntese óssea predomina nas crianças; em adultos normais, estes processos estão em equilíbrio, e entre $600 \mathrm{e}$ $700 \mathrm{mg}$ de cálcio são permutáveis todos os dias. 0 osso adulto inicia as perdas durante a quinta década, em ambos os sexos, mas avança mais rapidamente nas mulheres (Guyton, 1988).

A vitamina $D$ e o hormônio paratireoidiano desempenham papéis especialmente importantes no controle da intensidade com 
que o cálcio é reabsorvido pelo intestino, bem como a intensidade com que é excretado pelos rins e, também, a intensidade de sua absorção dos ossos (Guyton, 1988).

A biodisponibilidade de cálcio nos alimentos é um preocupação importante porque aproximadamente $75 \%$ das mulheres adultas e $60 \%$ dos homens adultos consomem menos do que a quantidade recomendável de $800 \mathrm{mg}$ de cálcio por dia (Poneros \& Erdman Júnior, 1989). Portanto, seria conveniente, ingerir alimentos que apresentem alta biodisponibilidade de cálcio para prevenir o desenvolvimento dessas doenças.

A adequação de um determinado nutriente na dieta não significa apenas ingestão desse nutriente em quantidades recomendadas. Um alimento pode ser rico em um determinado nutriente porém sua biodisponibilidade pode ser baixa. Deve-se considerar que nutrientes de fontes diferentes são absorvidos com diferentes graus de eficiência e que depois de absorvidos, sua utilização pode ser comprometida pela influência de outros componentes no alimento ou dieta, estado nutricional ou a forma química em que se encontra o nutriente (Miller, 1989). Torna-se então necessário, a ingestão de alimentos que apresentem alta biodisponibilidade para o nutriente em questão.

Não se tem ainda uma definição largamente aceita para o termo biodisponibilidade, que muitas vezes é substituído por 
disponibilidade, absorbilidade, absorção ou retenção (Miller, 1989). Encontramos desde definições simples como a sugerida por Greger (1988) que define biodisponibilidade como sendo a "utilidade (proveito) de nutrientes (em refeições, suplementos dietéticos ou alimentos individuais) por organismos vivos", ou a citada por Miller (1989) "biodisponibilidade de um elemento mineral ao organismo, é aquela proporção em meio nutriente, que é potencialmente absorvível em uma forma que é metabolicamente ativa". Esta última definiçăo é pouco prática uma vez que é difícil se determinar o grau de absorbalidade pois fatores fisiológicos estão envolvidos na absorção do cálcio, e, além disso, não leva em consideração o estado fisiológico de animais e humanos em estudo de biodisponibilidade de minerais.

Em estudos de biodisponibilidade de cálcio deve-se considerar o estado nutricional de cálcio do indivíduo e o efeito que a dieta exerce na excreção urinária de cálcio (efetuada pelo estado fisiológico e dieta). Uma outra definição para biodisponibilidade seria a eficiência da utilização de um nutriente em alimento ou dieta relativa a um padrão apropriado. Essa utilização pode ser quantificada pela medida da absorção, retenção corporal (balanço) ou outros parâmetros apropriados como: concentração tissular, massa corpórea, atividade enzimática, entre outras (Miller, 1989). Portanto para medirmos a biodisponibilidade de um nutriente temos de estudar o seu desempenho no organismo. 
Apesar das limitações metodológicas, os cientistas tem acumulado um grande número de informações sobre biodisponibilidade de cálcio. Entretanto, a maior dificuldade para uma avaliação da biodisponibilidade de cálcio de um alimento é que não é consumido sozinho, e, portanto, sofre influência de outros itens que compõem a dieta. O metabolismo de nutrientes está entrelaçado e muitas de suas interações podem resultar em mudanças que afetam a biodisponibilidade dos mesmos (Greger, 1988).

Segundo Berner et al. (1990), a biodisponibilidade de cálcio é influenciada pela natureza química do cálcio, alimento fonte e dos alimentos durante a refeição. Afirmam ainda que para que o cálcio possa ser absorvido, é necessário que seja solúvel. A solubilidade, portanto, seria um pré-requisito para absorção. Em relação a natureza química do cálcio, os produtos que contém fosfato de cálcio ou caseinato de cálcio são melhores absorvidos do que aqueles que o contém somente sob a forma iônica (Poneros \& Erdman Júnior, 1988).

Do ponto de vista de nutrição humana, o leite apresenta-se com destaque como sendo a principal fonte de cálcio. De acordo com Franco (1986), em $100 \mathrm{~g}$ de leite de vaca integral pasteurizado têm-se 123 mg de cálcio.

Segundo Coutinho (1981), alimentos de origem vegetal como agrião, alface, brócolis, couve-flor, couve-manteiga, couve-tronchuda, 
serralha fornecem boa quantidade de cálcio. A quantidade de cálcio na couve-flor, couve-manteiga e espinafre são $122 \mathrm{mg} / 100 \mathrm{~g}$, $330 \mathrm{mg} / 100 \mathrm{~g} \mathrm{e} 95 \mathrm{mg} / 100 \mathrm{~g}$ respectivamente (Franco, 1986).

Observa-se que as folhas acima citadas apresentam valores próximos e até maiores de cálcio em relação a fonte principal deste mineral que é o leite.

A composição dos alimentos é uma indicação muito valiosa de seu valor nutritivo, contudo não é suficiente para uma caracterização completa do alimento em estudo, do ponto de vista nutritivo. Isto porque raríssimos são os nutrientes contidos nos alimentos que se tornam disponíveis ao organismo após ingestão dos alimentos. A porção disponível de qualquer nutriente é aquela que efetivamente é absorvida em um forma que possa ser utilizada pelo organismo em seu metabolismo celular (Sgarbieri, 1987).

Existem vários fatores que interferem com a biodisponibilidade dos nutrientes presentes nos alimentos. Os mais importantes são digestibilidade, absorção, complexação e presença de substâncias tóxicas. Entre os fatores que interferem na eficiência da absorção do cálcio, aumentando a absorção desse mineral podemos citar: quantidades adequadas de vitamina $\mathrm{D}, \mathrm{pH}$ ácido na parte superior do trato intestinal e a motilidade normal do trato gastrointestinal. Por outro lado, grandes quantidades de gordura, fitatos, oxalatos podem 
formar compostos insolúveis com o cálcio interferindo na absorção intestinal (Mitchell et al.,1976).

Smith (1982) constatou que apesar de $15 \%$ dos vegetais analisados por ele conterem $150 \mathrm{mg}$ de cálcio em $100 \mathrm{~g}$, a disponibilidade fisiológica do cálcio inclui, até agora, discutiveis informações no conteúdo de oxalato dos vegetais folhosos.

A absorção de cálcio de vários alimentos fonte de cálcio tem sido avaliada em estudos com humanos e animais (Berner et al., 1990).

Os resultados demonstram que embora o cálcio esteja presente no espinafre, a sua biodisponibilidade é muito pobre, pois é um alimento rico em ácido oxálico o qual inibe a absorção do cálcio pela formação de sais insolúveis de oxalato de cálcio no intestino delgado. O cálcio dos vegetais que contém ácido oxálico tem biodisponibilidade menor do que o leite ou de vegetais que não 0 contém (Poneros \& Erdman Júnior, 1989).

Observou-se também que os valores obtidos para a biodisponibilidade relativa de cálcio do espinafre $(47 \%)$ e da mistura leite em pó desengordurado + espinafre $(52 \%)$ não diferem significativamente. Portanto, a biodisponibilidade relativa da mistura leite + espinafre também foi baixa, o que indica que o espinafre também interfere com a absorção de cálcio do leite. Esse fato sugere 
que o espinafre em uma refeição pode reduzir a biodisponibilidade de cálcio de outras fontes que são consumidas ao mesmo tempo.

Para avaliar a influência do ácido oxálico na absorção de cálcio, Weaver et al. (1987) utilizaram dietas contendo sais de cálcio e alimentos marcados intrinsecamente. Um grupo de ratos recebeu intraperitonealmente injeção com solução de cálcio, depois de mortos, avaliou-se a porcentagem do $\mathrm{Ca}$ no fêmur esquerdo. Foi observado que a biodisponibilidade de cálcio foi similar quando se utilizou $\mathrm{CaCl}_{2}$ e $\mathrm{CaCO}_{3}$ e couve (vegetal com baixo teor em ácido oxálico), enquanto que a biodisponibilidade de cálcio do oxalato de cálcio e espinafre foi aproximadamente 10 vezes menor do que aquelas fontes. Portanto, esses resultados sugerem que 0 ácido oxálico se liga ao cálcio tornando-o indisponível e que isso independe de uma possível interação com a fibra.

Berner et al. (1990) citam que a presença do oxalato em forma de espinafre é sugerido ser o fator que inibe a absorção de cálcio.

A solubilidade extremamente pobre do oxalato de cálcio sugere que alimentos contendo oxalato afetarão adversamente a ausorçãu de cálcio. O fato do oxalato afetar o cálcio de outras fontes na mesma refeição pode estar relacionado à proporção cálcio-oxalato no alimento, pois, se todo o oxalato estivesse presente como oxalato de cálcio, então não haveria oxalato livre para combinar com o cálcio de outras fontes. Entretanto, alguns vegetais folhosos con- 
têm grandes quantidades de oxalato solúvel o que pode reduzir a absorção de cálcio de outras fontes na mesma refeição (Miller, 1989).

Para verificar a biodisponibilidade de cálcio no espinafre, Kikanunga et al. (1988), forneceram para ratos com deficiência em cálcio, espinafre cru e espinafre fervido. Constataram que a absorção foi de apenas $27 \%$ e $36 \%$, respectivamente.

A biodisponibilidade de cálcio do leite e do cálcio proveniente do espinafre, também foi comparada por Heaney et al. (1988), em treze adultos sadios. Os resultados mostraram que a absorção média de cálcio do leite foi de $27,6 \%$ contra $5 \%$ do espinafre. Isto confirma que o cálcio no espinafre não está disponível rapidamente.

Com objetivo de verificar a disponibilidade de cálcio em alimentos que o contém em quantidades significativas, Poneros \& Erdman Júnior (1989) avaliaram a biodisponibilidade relativa de sementes de gergelim, farinha de amêndoa, leite em pó desengordurado, pão de trigo integral, espinafre e uma mistura de espinafre e leite em pó desengordurado. Verificou-se ainda o efeito da suplementação de algumas dietas $\left(\mathrm{CaCO}_{3}\right.$, amêndoa e leite em pó desengordurado) com ácido ascórbico na biodisponibilidade de cálcio. Utilizou-se como indicador da biodisponibilidade de cálcio, o conteúdo de cálcio na tíbia do animal (retenção de cálcio). Os resultados alcançados para biodisponibilidade foram: para $\mathrm{CaCO}_{3} \mathrm{e}$ 
leite em pó desengordurado (100\%); para pão de trigo integral $(95 \%)$; para farinha de amêndoa (66\%); para sementes de gergelim (65\%), para mistura de leite em pó desengordurado + espinafre (52\%); para o espinafre $(47 \%)$ e a dieta controle (caseína- $\mathrm{CaCO}_{3}$ ) foi fixado como $100 \%$.

Esses resultados demonstram que embora o cálcio esteja presente no espinafre, a sua biodisponibilidade é muito pobre, pois é um alimento rico em ácido oxálico o qual inibe a absorção do cálcio pela formação de sais insolúveis de oxalato de cálcio no intestino delgado. E, segundo Kelsay \& Prather (1983), o cálcio dos vegetais que contém ácido oxálico tem biodisponibilidade menor do que o leite ou de vegetais que não o contém. Também foram observados que os valores obtidos para biodisponibilidade relativa de cálcio do espinafre (47\%) e da mistura leite em pó desengordurado + espinafre $(52 \%)$ não diferiram significativamente.

Os valores de biodisponibilidade relativa de cálcio alcançados para a farinha de amêndoas (66\%) e para as sementes de gergelim (65\%) foram baixos quando comparados com os do pão de trigo integral (95\%). Isto pode ser explicado, segundo Poneros \& Erdman Júnior (1989) devido aos elevados níveis de ácido fítico encontrados para ambos, pois esse componente forma precipitados insolúveis com vários minerais tornando-os indisponíveis para a absorção. 
Poneros \& Erdman Júnior (1989) ressaltam os principais pontos de seu estudo afirmando que o leite em pó desengordurado e o pão de trigo integral fortificado com cálcio o contém na forma altamente biodisponivel; que a farinha de amêndoa e as sementes de gergelim apresentam um nível intermediário de cálcio biodisponível; que o espinafre não somente apresenta uma pobre biodisponibilidade de cálcio do leite em pó desengordurado se consumidos na mesma refeição; que o cálcio biodisponível ao animal influência a composição mineral do osso e que o ácido ascórbico não exerce efeito sobre a biodisponibilidade de cálcio quando se utiliza experimentos com ratos. Berner et al. (1990) concluem que o cálcio do leite é mais claramente absorvível do que do espinafre. 


\section{MATERIAL E MÉTODOS}

\subsection{Matérias-primas}

As matérias-primas utilizadas neste trabalho foram alimentos de origem vegetal com teor considerável em cálcio; como as folhas de couve-manteiga (Brassica oleracea, variedade acephala), folhas de couve-flor (Brassica oleracea, variedade botrytis), folhas de espinafre (Spinacia oleracea). As folhas foram adquiridas no comércio local e a folha de espinafre foi adquirida também de outros dois locais, ou seja, da Fazendinha da UNIMEP e da horta do Departamento de Horticultura da ESALQ/USP.

\subsection{Preparo dos ingredientes}

As folhas de couve-manteiga, couve-flor e espinafre depois de lavadas, foram secas em estufa, com circulação forçada de ar, a temperatura de $55-60^{\circ} \mathrm{C}$, até peso constante (AOAC,1975). Em seguida foram moídas e peneirada a 20 "mesh", para posterior utilização no ensaio biológico e análises químicas. 


\subsection{Ensaio biológico para avaliação protéica}

\subsubsection{Preparo das dietas}

As dietas experimentais e a controle (caseína) foram formuladas de acordo com o estabelecido pela AOAC (1975), ou seja, a nível de $10 \%$ de proteína, $8 \%$ de óleo de milho, $1 \%$ de mistura vitamínica, $4 \%$ de mistura salina e o amido de milho para completar $100 \%$. Foram preparadas, dieta controle de caseína e dieta aprotéica (a fim de corrigir a proteína consumida e eliminada para fins de cálculo de digestibilidade e utilização protéica líquida). Foram elaboradas cinco dietas, denominadas da seguinte forma:

- Dieta I: folhas de couve-manteiga

- Dieta II: folhas de couve-flor

- Dieta III: folhas de espinafre

- Dieta IV: caseína (Controle)

- Dieta V: aprotéica.

\subsubsection{Animais}

Foram utilizados ratos cos machos, desmamados (Rattus norvegicus, variedade albinos nhagem Wistar), com idade de 21 a 23 dias e com uma variação de peso não mais de $5 \%$ dentro do grupo. Cada dieta do ensaio biológico foi testada com seis animais. Os animais ficaram em gaiolas individuais, alimentados com as dietas experimentais e controle. A água foi fornecida "ad libitum". $\mathrm{O}$ 
peso e o consumo de alimentos foram registrados três vezes por semana, durante os 28 dias de duração do experimento.

As fezes totais excretadas pelos ratos, foram coletadas todos os dias do experimento, secas em estufa a $105^{\circ} \mathrm{C}$, moídas e pesadas. Uma amostra total de cada grupo foi retirada para verificar o teor de nitrogênio. No vigésimo oitavo dia, após jejum de 12 horas, todos os animais foram sacrificados. As cavidades abdominal, torácica e craniana foram abertas e secas a $105^{\circ} \mathrm{C}$ até peso constante (aproximadamente 72 horas), em seguida foram moídos em liqüidificador industrial e o nitrogênio da carcaça e das fezes foi determinado segundo o método descrito pela AOAC (1975).

\subsection{3 Índices da qualidade protéica}

a) Digestibilidade: é a medida da porcentagem das proteínas que são hidrolisadas pelas enzimas digestivas e absorvidas na forma de aminoácidos ou de qualquer outro composto nitrogenado. O seu cálculo pode ser representado pela seguinte fórmula:

$D=$ Prot. consumida (24h) - [Prot. excretada (24h) - Prot. excretada pelo grupo aprotéico (24 h)] $\times 100$ Protelna consumida

b) Utilização protéica líquida (NPU): é a quantidade de nitrogênio retido no organismo em relação ao nitrogênio ingerido, que pode ser descrito da seguinte forma: 


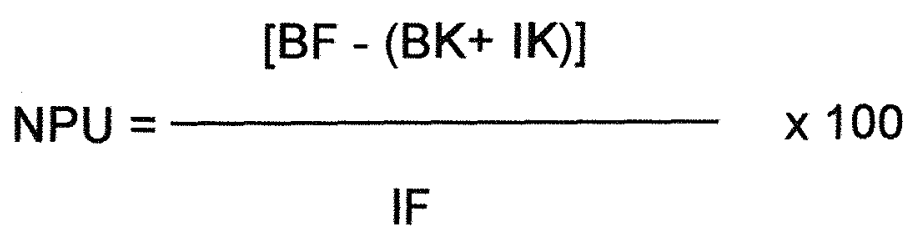

Onde: $\quad B F=$ nitrogênio da carcaça do grupo experimental; IF = nitrogênio ingerido; $\mathrm{BK}=$ nitrogênio da carcaça do grupo aprotéico; e IK = nitrogênio ingerido pelo grupo aprotéico.

c) Valor biológico: é a quantidade de nitrogênio absorvido que será retido pelo organismo, o qual é representado pela seguinte fórmula:

NPU

$\mathrm{VB}=-\times 100$

D

d) Coeficiente de eficiência protéica (PER): é o ganho de peso corporal em gramas pela quantidade de proteína ingerida em gramas, representado pela seguinte fórmula:

Ganho de peso (g)

PER =

Consumo de proteína da dieta $(\mathrm{g})$ 
e) Coeficiente de eficiência alimentar (CEA): é o ganho de peso corporal em gramas pela quantidade de ração consumida em gramas, representada pela seguinte fórmula:

$$
\text { CEA }=\frac{\text { Ganho de peso }(\mathrm{g})}{\text { Consumo de dieta }(\mathrm{g})}
$$

\subsection{Ensaio biológico de biodisponibilidade de cálcio}

\subsubsection{Preparo das dietas}

As dietas experimentais e a de controle caseína foram formuladas de acordo com o estabelecido pela AOAC (1975), ou seja, a nível de $10 \%$ de proteína, $8 \%$ de óleo de milho, $1 \%$ de mistura vitamínica, $4 \%$ de mistura salina e o amido de milho para completar $100 \%$. A mistura salina utilizada foi isenta de cálcio, nas dietas experimentais, sendo o teor deste mineral fornecido pelo seu conteúdo na folha.

As dietas controle de caseína continham $\mathrm{CaCO}_{3}$ como fonte de cálcio cuja quantidade foi igual a da dieta experimental para comparação. 
As dietas empregadas estão descritas à seguir:

- Dieta A: Dieta experimental com folha de couve-manteiga

- Dieta B: Dieta controle caseína com teor de cálcio correspondente ao da folha de couve-manteiga

- Dieta C: Dieta experimental com folha de couve-flor

- Dieta D: Dieta controle caseína com teor de cálcio correspondente ao da folha de couve-flor

- Dieta E: Dieta experimental com folha de espinafre

- Dieta F: Dieta controle caseína com teor de cálcio correspondente ao da folha espinafre.

As dietas empregadas foram preparadas uma única vez para utilização durante todo o experimento.

As dietas experimentais e as respectivas controles continham as seguintes quantidades de cálcio ( $\mathrm{Ca}$ ):

- Dietas A e B: $3,10 \% \mathrm{Ca}$

- Dietas C e D: $3,93 \% \mathrm{Ca}$

- Dietas E e F: $1,17 \% \mathrm{Ca}$

\subsubsection{Animais}

Foram utilizados ratos brancos, machos, desmamados (Rattus norvegicus, variedade albinos, linhagem Wistar). Os animais tinham de 21 a 23 dias de idade com uma variação de peso não mais de $5 \%$ dentro do grupo, com um número de seis animais por dieta. 
Os animais foram mantidos em gaiolas individuais, em um ambiente de temperatura e luz controladas. Foram alimentados com as dietas experimentais. A água foi fornecida "ad libitum".

A ingestão e o ganho de peso foram monitorados, três vezes por semana, durante os 30 dias do experimento. No final do experimento os animais foram mortos por "overdose" de éter.

O fêmur direito de cada animal foi retirado e em seguida colocado no freezer por 12 horas. Posteriormente foram limpos, pesados e secados a temperatura de $105^{\circ} \mathrm{C}$, por 72 horas até peso constante. Em seguida foram triturados e feita a digestão nitro perclórica, para verificação da retenção de cálcio pelos animais.

A biodisponibilidade de cálcio foi determinada de acordo com Poneros \& Erdman Júnior (18), conforme mostra a fórmula a seguir:

Cálcio retido no fêmur $(\mathrm{mg})$

Biodisponibilidade $=$ de cálcio

Consumo de cálcio da dieta (g) 


\subsubsection{Análises químicas}

Os teores de matéria seca, proteína bruta, extrato etéreo, fibra bruta e cinzas das farinhas de folhas foram determinadas de acordo com AOAC (1975).

Os teores de cálcio das farinhas das folhas e do fêmur foram determinados através de espectrometria de absorção atômica (Sarruge \& Haag, 1974).

A metodologia empregada para verificar o teor de ácido fítico nas farinhas das folhas foi desenvolvida por Grynspan \& Cherya (1989)

A determinação do oxalato foi realizada segundo método volumétrico de Moir (1953) que consiste na solubilização do oxalato em solução de ácido clorídrico, seguida de precipitação e titulação com solução de $\mathrm{KMnO}_{4}$.

A digestão "in vitro" foi determinada segundo o método proposto por Akenson \& Stahman (1964). 


\subsubsection{Análise estatística}

O delineamento experimental foi inteiramente ao acaso, utilizando o Teste de Tukey e estabelecendo $p<0,05$ como nivel de significância (Gomes, 1982). O programa estatístico utilizado foi o SAS (Statistical Analysis System) desenvolvido pelo SAS Institute Inc. 


\section{RESULTADOS E DISCUSSÃO}

\subsection{Parâmetros químicos}

\subsubsection{Composição centesimal}

Os resultados da composição centesimal das farinhas experimentais encontram-se na Tabela 1. Pode-se observar através dos resultados que houve diferença estatística significativa $(p<0,05)$ entre as três folhas( couve-manteiga, couve-flor e espinafre), exceto em relação a matéria seca, onde as folhas de couve-flor e espinafre apresentaram resultados semelhantes.

Observa-se que a folha de couve-flor, destacou-se em todos os resultados, diferenciando somente para teores de cinzas. O teor de cinzas da folha de espinafre foi de $19,7 \%$, valor este que diferiu estatisticamente $(p<0,05)$ das folhas de couve-manteiga com $15,4 \%$ e couve-flor com $13,7 \%$. 
Tabela 1. Composição centesimal $(\mathrm{g} / 100 \mathrm{~g})$ das folhas desidratadas de couve-manteiga, couve-flor e espinafre.

\begin{tabular}{lllccc}
\hline Folhas & $\begin{array}{l}\text { Proteina } \\
\text { Bruta } \\
(\%)\end{array}$ & $\begin{array}{c}\text { Extrato } \\
\text { Etéreo } \\
(\%)\end{array}$ & $\begin{array}{c}\text { Fibra } \\
\text { Bruta } \\
(\%)\end{array}$ & $\begin{array}{c}\text { Cinzas } \\
(\%)\end{array}$ & $\begin{array}{c}\text { Matéria } \\
\text { Seca } \\
(\%)\end{array}$ \\
\hline Couve-manteiga & $18,7^{\mathrm{c}}$ & $4,8^{\mathrm{b}}$ & $13,4^{\mathrm{b}}$ & $15,4^{\mathrm{b}}$ & $88,1^{\mathrm{b}}$ \\
Couve-flor & $35,1^{\mathrm{a}}$ & $5,9^{\mathrm{a}}$ & $14,3^{\mathrm{a}}$ & $13,7^{\mathrm{c}}$ & $92,2^{\mathrm{a}}$ \\
Espinafre & $28,6^{\mathrm{b}}$ & $1,7^{\mathrm{c}}$ & $11,1^{\mathrm{c}}$ & $19,7^{\mathrm{a}}$ & $92,7^{\mathrm{a}}$ \\
\hline
\end{tabular}

$\left(^{*}\right)$ Os valores com letras diferentes na vertical diferem significativamente $(p<0,05)$.

A folha de couve-flor apresentou resultado significativo, para teor protéico com $35,1 \%$, valor superior ao encontrado por Gupta \& Wagle (1988), de $23,65 \%$. Com relação ao espinafre o valor protéico foi de $28,6 \%$, resultado superior ao encontrado por Gupta \& Wagle (1988) de $21,59 \%$. A folha de couve-manteiga apresentou resultado inferior as demais dietas, porém foi superior ao resultado encontrado por Salgado et al. (1982) com 4,5\%.

Embora a melhor fonte protéica seja de origem animal, a folha de couve-flor destacou-se pelo seu alto teor protéico. As proteínas de origem vegetal, são classificadas como incompletas, pois nelas os aminoácidos essenciais são limitantes. Entretanto as proteínas dos vegetais constituem uma parte importante das refeiçōes de milhões de pessoas nos países em desenvolvimento, com baixo poder 
aquisitivo e que não têm acesso as proteínas de origem animal (Anderson et al.,1977).

Em relação ao extrato etéreo, a folha de couve-flor com 5,9\% diferiu estatisticamente das demais dietas, cujo resultado foi superior ao apresentado por Gupta \& Wagle (1988) com 3,73\%. A folha de couve-flor também apresentou resultado superior para o teor de fibra bruta com $14,3 \%$, o qual diferiu estatisticamente das dietas com folhas de couve-manteiga e espinafre. Os teores de fibra bruta destas folhas foram significativos; elas são úteis em estimular os movimentos peristálticos intestinais, favorecendo as evacuações. Além de combaterem a constipação intestinal, auxiliam a diminuir a incidência de doenças ano-retais e a baixar o teor de colesterol e triglicerídeos no sangue (Gonsalves, 1992).

\subsubsection{Digestibilidade "in vitro"}

A digestibilidade das proteínas é considerada um indicador de sua qualidade. Tendo em vista sua importância, os teores de digestibilidade "in vitro" das farinhas das folhas, são mostrados na Tabela 2. 
Tabela 2. Digestibilidade "in vitro" nas farinhas das folhas de couve-manteiga, couve-flor e espinafre.

Farinhas

Digestibilidade "in vitro"

(\%)

Folha de couve manteiga

$74,3^{a^{*}}$

Folha de couve-flor

$63,7^{b}$

Folha de espinafre

$58,2^{\circ}$

$\left.{ }^{\star}\right)$ Os valores com letras diferentes na vertical diferem significativamente $(p<0,05)$.

Observa-se na Tabela 2 que houve diferença significativa $(p<0,05)$ entre as dietas; a farinha de couve-manteiga apresentou 0 melhor resultado. A digestibilidade dos alimentos de origem vegetal é normalmente influenciada por alguns fatores como: (1) presença de fatores antinutricionais, sendo que entre as dietas estudadas a folha de espinafre apresenta teores de ácido fítico e ácido oxálico muito superiores as demais folhas como será discutido a seguir no item 3.3; (2) A forma e a seqüência de como esses aminoácidos serão liberados pelas enzimas digestivas, uma vez que, dependendo da sua origem, cada fonte de proteína tem sua própria digestibilidade e diferente taxa de liberação de aminoácidos (Brulé \& Savoie, 1988). 


\subsection{Ensaio biológico para avaliação protéica}

\subsubsection{Parâmetros nutricionais}

Pode-se observar na Tabela 3 que a dieta padrão de caseína apresentam resultados superiores nos parâmetros nutricionais estudados. Esse resultado era aguardado, devido a excelência da qualidade protéica de caseína, a qual possui todos os aminoácidos essenciais em proporções adequadas qualitativa e quantitativamente.

Tabela 3. Ganho de peso, consumo de ração, coeficiente de eficiência alimentar (CEA), coeficiente de eficiência protéica (PER), digestibilidade (D), utilização protéica líquida (NPU) e valor biológico (VB), obtidos para dietas experimentais e controle.

\begin{tabular}{lllllccc}
\hline Dieta & Ganho & Consumo & CEA & PER & D & NPU & VB \\
& de peso & de Ração & & & $(\%)$ & $(\%)$ & $(\%)$
\end{tabular}

Folha Couve-

$\begin{array}{llllllll}\text { manteiga } & 76,0^{\mathrm{b}^{*}} & 312,7^{\mathrm{b}} & 0,24^{\mathrm{b}} & 2,4^{\mathrm{b}} & 73,9^{\mathrm{b}} & 32,3^{\mathrm{b}} & 43,7^{\mathrm{b}} \\ \text { Folha Couve-flor } & 69,0^{\mathrm{b}} & 305,3^{\mathrm{b}} & 0,23^{\mathrm{b}} & 2,2^{\mathrm{b}} & 62,0^{\mathrm{c}} & 25,5^{\mathrm{c}} & 41,0^{\mathrm{c}} \\ \text { Caseína } & 130,3^{\mathrm{a}} & 378,0^{\mathrm{a}} & 0,34^{\mathrm{a}} & 3,4^{\mathrm{a}} & 92,2^{\mathrm{a}} & 80,6^{\mathrm{a}} & 87,4^{\mathrm{a}}\end{array}$

${ }_{(*)}$ Os valores com letras diferentes na vertical diferem significativamente $(p<0,05)$. 
As dietas da folha de couve-manteiga e couve-flor não apresentaram diferenças estatísticas significativas $(p<0,05)$ para os teores de ganho de peso, consumo de ração, CEA e PER. Com relação aos parâmetros de NPU, D e VB, a dieta de folha de couvemanteiga apresentou resultado superior ao encontrado pela folha de couve-flor, conforme observado na Tabela 3 , isto sugere que a absorção de aminoácidos nesta dieta foi mais eficaz.

\subsection{Fatores antinutricionais}

Através da Tabela 4, verifica-se que houve diferença estatística significativa $(p<0,05)$, entre os teores de ácido fítico e ácido oxálico nas farinhas estudadas. Através da Figura 1, podemos visualizar melhor a diferença existente nos teores de ácido fítico e oxálico, sendo que a farinha de folha de couve-manteiga apresentou o menor teor para ambos os ácidos. Conforme podemos observar a farinha com folha de espinafre apresentou um resultado bem superior as demais folhas. Como conseqüência desse fato, os animais alimentados com a dieta de folha de espinafre morreram na primeira semana, portanto, não puderam ser avaliados. Várias tentativas foram feitas, inclusive com a dieta com folha de espinafre cozida, folha de espinafre provenientes de outros locais também foram testados. Repetiu-se os mesmos resultados, ou seja, a morte dos animais com hemorragias, tremores e perda de peso. Os rins destes animais mortos foram retirados e analisados pela Faculdade de Odontologia de Piracicaba/UNICAMP, no Departamento de Pato- 
logia, cujos resultados foram: inchaço tubular renal, indicando uma nefrotoxicidade, edema celular, depósito de substâncias aparentemente cristalizadas nos túbulos renais, o qual provoca disfunção renal. Este resultado está de acordo com o relatado por Durigan et al. (1987), o qual atribuíram ao ácido oxálico a conseqüência causada pela ingestão de plantas ricas nesta substância, em que os sintomas foram lesões corrosivas na boca e trato-intestinal, hemorragias gástricas e cólica renal.

Tabela 4. Ácido fítico ( $\mathrm{mg} / \mathrm{g}$ amostra) e ácido oxálico (\%) nas farinhas de folhas de couve-manteiga, couve-flor e espinafre.

Farinhas

Ácido fítico

$\mathrm{mg} / \mathrm{g}$

$$
\begin{aligned}
& 2,6^{\mathrm{c}^{*}} \\
& 5,8^{\mathrm{b}}
\end{aligned}
$$

$16,3^{a}$

Folha de espinafre

$\begin{array}{rr}2,6^{c^{*}} & 0,72^{c} \\ 5,8^{b} & 1,63^{b} \\ 16,3^{a} & 12,41^{a}\end{array}$

$\left.{ }^{*}\right)$ Os valores com letras diferentes na vertical diferem significativamente $(p<0,05)$.

De acordo com Ferrando (1980), a presença de ácido oxálico em um alimento além de causar um balanço negativo de cálcio, em doses superiores a $2 \mathrm{~g} / \mathrm{kg}$ de peso vivo, pode causar toxicidade nos rins e o ácido fítico na proporção de $1 \%$ na dieta pode causar redução no crescimento de ratos jovens. Segundo este mesmo autor 
o espinafre que possui a relação de ácido oxálico/cálcio superior a 3 deve ser evitado.

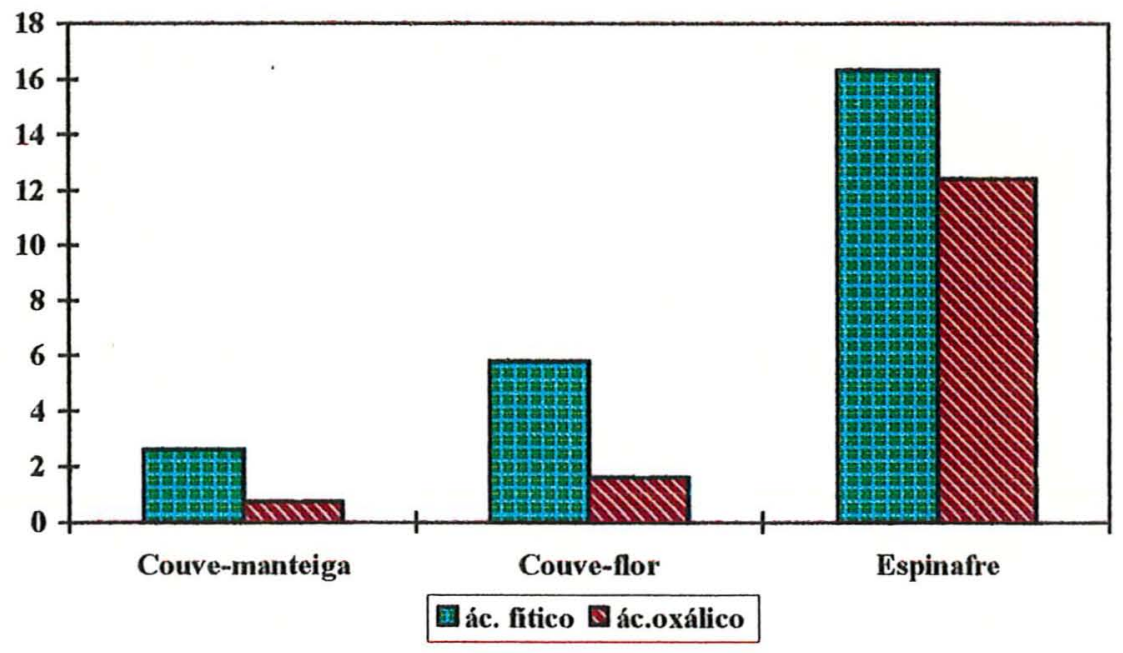

Figura 1- Ácido fítico (mg/g) e ácido oxálico (\%) nas farinhas de folhas de couve-manteiga, couve-flor e espinafre.

\subsection{Biodisponibilidade de cálcio}

A quantidade de cálcio no fêmur foi usada como um indicador da biodisponibilidade do cálcio, uma vez que reflete a retenção deste mineral pelo rato (Poneros \& Erdman Júnior, 1989). 
Tabela 5. Biodisponibilidade de cálcio na folha de couvemanteiga.

\begin{tabular}{lcccccc}
\hline Dieta & $\begin{array}{c}\text { GP } \\
(\mathrm{g})\end{array}$ & $\begin{array}{c}\text { CR } \\
(\mathrm{g})\end{array}$ & $\begin{array}{c}\text { CAD } \\
(\mathrm{g})\end{array}$ & $\begin{array}{c}\text { CRF } \\
(\mathrm{mg})\end{array}$ & $\begin{array}{c}\text { BIO } \\
(\mathrm{mg} / \mathrm{g})\end{array}$ & $\begin{array}{c}\mathrm{RC} \\
(\%)\end{array}$ \\
\hline Folha de couve-manteiga & $79,0^{\mathrm{b}^{\mathrm{b}}}$ & $324,7^{\mathrm{b}}$ & $5,4^{\mathrm{b}}$ & $7,7^{\mathrm{b}}$ & $1,43^{\mathrm{b}}$ & $73,0^{\mathrm{b}}$ \\
Controle (caseína) & $110,8^{\mathrm{a}}$ & $355,6^{\mathrm{a}}$ & $5,9^{\mathrm{a}}$ & $11,0^{\mathrm{a}}$ & $1,96^{\mathrm{a}}$ & $100,0^{\mathrm{a}}$
\end{tabular}

OBS: GP (ganho de Peso), CR (consumo de ração), CAD (consumo de cálcio da dieta), CRF (cálcio retido no fêmur), BIO (biodisponibilidade) e RC (retenção de cálcio). ( $\left.{ }^{*}\right)$ Os valores com letras diferentes na vertical diferem significativamente $(p<0,05)$.

Tabela 6. Biodisponibilidade de cálcio na folha de couve-flor.

\begin{tabular}{|c|c|c|c|c|c|c|}
\hline Dieta & $\begin{array}{l}\text { GP } \\
\text { (g) }\end{array}$ & $\begin{array}{l}\text { CR } \\
\text { (g) }\end{array}$ & $\begin{array}{l}\text { CAD } \\
(g)\end{array}$ & $\begin{array}{l}\text { CRF } \\
(\mathrm{mg})\end{array}$ & $\begin{array}{c}\mathrm{BIO} \\
(\mathrm{mg} / \mathrm{g})\end{array}$ & $\begin{array}{l}\mathrm{RC} \\
(\%)\end{array}$ \\
\hline Folha de couve-flor & $71,0^{b^{*}}$ & $321,6^{b}$ & $2,44^{b}$ & $4,3^{b}$ & $1,19^{b}$ & $69,5^{b}$ \\
\hline Controle (caseína) & $103,2^{a}$ & $352,0^{a}$ & $3,21^{a}$ & $6,7^{\mathrm{a}}$ & $1,71^{a}$ & $100,0^{a}$ \\
\hline
\end{tabular}

OBS: GP (ganho de Peso), CR (consumo de ração), CAD (consumo de cálcio da dieta), CRF (cálcio retido no fêmur), BIO (biodisponibilidade) e RC (retenção de cálcio). ( $\left.{ }^{*}\right)$ Os valores com letras diferentes na vertical diferem significativamente $(p<0,05)$. 
Tabela 7. Biodisponibilidade de cálcio na dieta com folhas couve-manteiga e couve-flor.

\begin{tabular}{lcccccccc}
\hline $\begin{array}{l}\text { Dieta } \\
\text { (Folhas) }\end{array}$ & GP & CR & CAD & CRF & BIO & RC & CAF & CAO \\
$(\mathrm{g})$ & $(\mathrm{g})$ & $(\mathrm{g})$ & $(\mathrm{mg})$ & $(\mathrm{mg} / \mathrm{g})$ & $(\%)$ & $(\mathrm{g})$ & $(\mathrm{g})$ \\
\hline Couve-manteiga & $79,0^{\mathrm{a}}$ & $324,7^{\mathrm{a}}$ & $5,4^{\mathrm{a}}$ & $7,7^{\mathrm{a}}$ & $1,43^{\mathrm{a}}$ & $73,0^{\mathrm{b}}$ & $0,45^{\mathrm{b}}$ & $1,2^{\mathrm{b}}$ \\
Couve-flor & $71,0^{\mathrm{b}}$ & $321,6^{\mathrm{b}}$ & $3,6^{\mathrm{b}}$ & $4,3^{\mathrm{b}}$ & $1,19^{\mathrm{b}}$ & $69,5^{\mathrm{a}}$ & $0,51^{\mathrm{a}}$ & $1,48^{\mathrm{a}}$ \\
\hline
\end{tabular}

OBS: GP (ganho de Peso), CR (consumo de ração), CAD (consumo de cálcio da dieta), CRF (cálcio retido no fêmur), BIO (biodisponibilidade), RC (retenção de cálcio), CAF (consumo de ácido fítico) e CAO (consumo de ácido oxálico). (*) Os valores com letras diferentes na vertical diferem significativamente $(p<0,05)$.

Observa-se através das Tabela 5 e 6 , que houve uma diferença estatística significativa $(p<0,05)$ entre as dietas experimentais, cujo melhor resultado foi encontrado na dieta controle (caseína). Esse resultado era aguardado, uma vez que, a dieta controle não continha a presença dos ácidos oxálicos e fíticos que interferem com a biodisponibilidade do cálcio (Graf \& Eaton, 1985).

Mesmo havendo uma biodisponibilidade maior para os controles, observa-se que houve retenção de cálcio pelos animais, provenientes das dietas das folhas de couve-manteiga e couve-flor, ou seja, $73 \%$ e $69,5 \%$ respectivamente.

Através da Tabela 7, verifica-se que houve diferença estatística significativa $(p<0,05)$ entre ambas as dietas, sendo a biodisponi- 
bilidade de cálcio maior na dieta de folha de couve-manteiga. Em relação ao cálcio retido no fêmur podemos observar que os animais da dieta contendo farinha de couve manteiga apresentou resultados superiores aos animais alimentados com a folha de couve-flor (Figura 2).

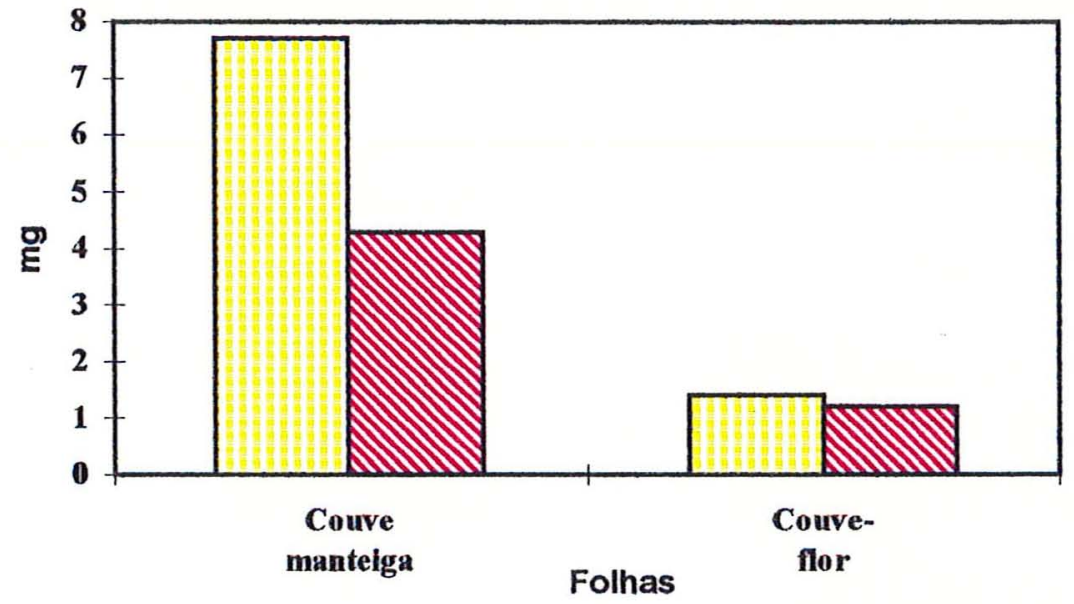

口Cálcio retido no fêmur Q Biodisponibilidade

Figura 2 - Cálcio retido no fêmur (CRF) e a biodisponibilidade de cálcio $(\mathrm{BIO})$ nas folhas de couve-manteiga e couveflor. 


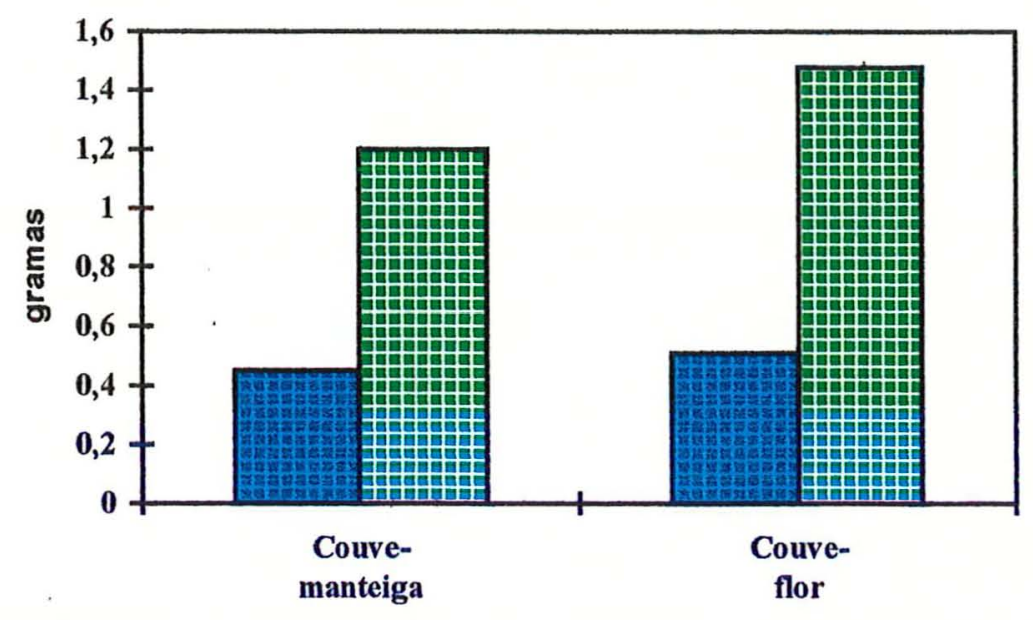

Folhas

Figura 3 - Consumo de ácido fítico (CAF) e ácido oxálico (CAO) nas folhas de couve-manteiga e couve-flor.

Através da Figura 3 podemos observar que o consumo de ácido fítico e ácido oxálico foi maior na dieta contendo folha de couve-flor; esse resultado é justificado, uma vez que, essas folhas apresentaram teores superiores para ácido oxálico e ácido fítico $(1,63 \%)$ e $(5,8 \mathrm{mg} / \mathrm{g})$ quando comparado com a folha de couvemanteiga que foi de $0,72 \%$ e $2,6 \mathrm{mg} / \mathrm{g}$ respectivamente. 


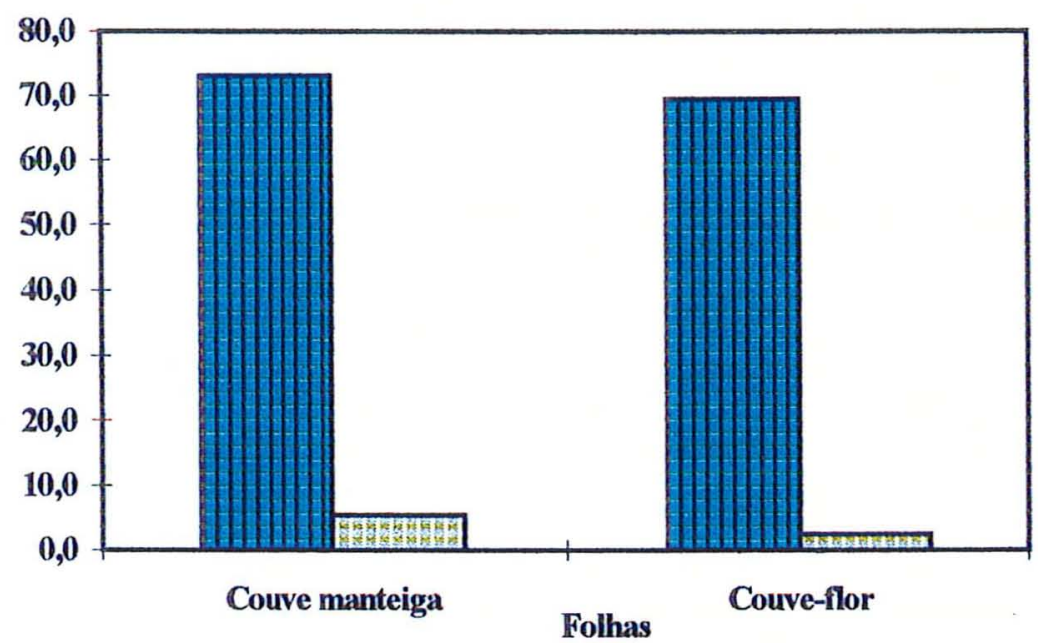

⿴囗十 Retenção cálcio (\%) ๑ Consumo de Ca (g)

Figura 4 - Retenção de cálcio (RC) e consumo de cálcio da dieta (CAD) nas follhas de couve-manteiga e couve-flor.

Observando a Figura 4 podemos perceber que os animais alimentados com as folhas de couve-flor consumiram e retiveram menor concentração de cálcio, quando comparado com os animais alimentados com a folha de couve-manteiga. Devido a maior concentração de ácido fítico e principalmente oxálico, o cálcio da folha de couve-flor não estava disponível, principalmente, o ácido oxálico inibe a absorção do cálcio pela formação de sais insolúveis de oxalato de cálcio no intestino delgado. Esse fato não ocorreu com animais alimentados com a folha de couve-manteiga por apresentarem teores de ácido fítico e oxálico inferiores ao da folha de couve-flor. 


\section{CONCLUSÕES}

Do presente trabalho foram apresentadas as seguintes conclusões:

- A análise química mostrou que os teores de proteína da folha de couve-flor foi superior as demais folhas;

- A análise da qualidade protéica mostra ser a proteína da folha de couve-manteiga melhor do ponto de vista nutricional;

- Os animais alimentados com a dieta da folha de couvemanteiga apresentaram melhor biodisponibilidade e retenção de cálcio $(73 \%)$ nos ossos;

- O elevado teor de ácido oxálico, bem como a presença de outros fatores antinutricionais na folha de espinafre mostrou ser essa folha prejudicial à saúde dos animais estudados. 


\section{REFERÊNCIAS BIBLIOGRÁFICAS}

AKESON, W.R. ; STAHMAN, M.A. A pepsin pancreatin digest index of protein quality evaluation. Journal of Nutrition, v.83, p. 257$361,1964$.

ANDERSON, I.; DIBBLE, M.V.; MITCHELL, H.S.; RYNBERGIN, H.J. Nutrición humana. Principios y aplicaciones. Madri:Bellaterra, 1977. 349p.

ASSOCIATION OF OFFICIAL AGRICULTURE CHEMISTS. Official methods of analysis association of official agriculture chemists. 12 ed. Washington, 1975, 1018p.

BERNER, L.A. ; McBEAN, L.D. ; LOFGREN, P.A. Calcium and chronic disease prevention: Challengens to the food industry. Food Technology, v.44, n.3, p.50-57, 66-70, 1990.

BRULÉ, D. ; SAVOIE, L. In vitro digestibility of protein and aminoacids in protein mixtures. Journal Science Food Agriculture, v.43, n.4, p. 361-372, 1988.

COUTINHO, R. Cálcio: In: . Noções de fisiologia da nutrição. Rio de Janeiro: Cultura Médica, 1981. cap.10, p.173195. 
DURIGAN, J.F. Fatores antinutricionais em alimentos. Piracicaba: ESALQ/USP Depto. Economia Doméstica, p.155-224, 1989.

DURIGAN, J.F.; SGARBIERI, V.C.; ALMEIDA, L.D. Antinutricional factores and toxicity in raw dry beans (Phaseolus vulgaris, $L$ ) of 12 brasilian cultivars. Journal Food Biochemistry, v.11, p.185-187, 1987.

ERDMAN JÚNIOR, J.W. Biovailability of trace minerals from cereals and legumes. Cereal Chemistry, v.58, n.1, p.21-26, 1981.

FERRANDO, R. Alimentos tradicionales y no tradicionales. Alimentación y Nutritición, v.2, p.31-35, 1980.

FRANCO, G. Tabela de composição química dos alimentos. Rio de Janeiro: Atheneu, 1986. p. 41-85.

GOMES, P.F. Curso de estatística experimental. São Paulo:Nobel, 1982. 430p.

GONSALVES, P.E. Livro dos alimentos. São Paulo:Martins Fontes, 1992. 265p.

GRAF, E. Calcium binding to phitic acid. Journal of Agricultural and Food Chemistry, v.31, n.4, p.851-855, 1983. 
GRAF, E.; EATON, J.W. Dietary phytate and calcium bioavailability. In: NUTRITIONAL BIOAVAILABILITY OF CALCIUM. Washington: American Chemical Society, 1985. cap.5, p.51-62.

GREGER, J.L. Calcium biovailability. Cereal Foods World, v.33, n.9, p.796-800, 1988.

GRYNSPAN, F.; CHERYAN, M. Phytate-calcium interactions with soy protein. Journal of the American Oil Chemists Society, v.66, n.1, p.93-97, 1989.

GUPTA, K.; WAGLE, D.S. Nutritional and antinutritional factors of green leafy vegetables. Journal of Agricultural and Food Chemistry, v.36, p.472-474, 1988.

GUYTON, A.C. Fisiologia humana. São Paulo: Guanabara Koogan, 1988. $925 p$.

HEANEY, R.P. ; WEAVER, C.M. ; RECKER, R.R. Calcium absorbality from spinach. American Journal of Clinical Nutrition, v.47, n.4, p.707-709, 1988. 
KELSAY, R.P. ; PRATHER, E.S. Mineral balances of human subjects consuming spinach in a low - fiber diet and in a diet containing fruits and vegetables. The American Journal of Clinical Nutrition, v.38, n.1, p.12-19, 1983.

KIKANUNGA, S. ; ARIMORI, M. ; TAKAHASHI, M. The biovailability of calcium in spinach and calcium oxalate to calcium deficient rats. Journal of Nutritional Science and Vitaminology, v.34, n.2, p.195-207, 1988.

KRAUSE, M.V. ; MAHAN, L.K. Alimentos, nutrição e dietoterapia. São Paulo: Rocca, 1994. 957p.

LONNERDAL, B. ; SANDBERG, A.S.; SANDSTRON, B.; KUNZ, C. Inhibitory effects of phytic acid and other inositol phosphates on zinc and calcium absorption in suckling rate. The Journal of Nutrition, v.119, n. 2, p. 211-214, 1980.

MCCARRON, D.A. Blood pressure and nutrient intake in the United States. Science, v.224, p.1392-1394, 1984.

MILLER, D.D. Calcium in the diet: Food sources, recommended intakes and nutritional biovailability. ADVANCES IN FOOD AND NUTRITION RESEARCH, v.33, pg.103-156, 1989. 
- MITCHELL, H.S. ; RYNBERGEN, H.J. ; ANDERSON, L. ; DIBBLE, M.V. Metabolism mineral, nutrição. Rio de Janeiro: Atheneu, 1991. cap. 6, p. 63-69.

MITCHELL, H.S.; RYNBERGEN, H.J.; ANDERSON, L.; DIBBLE, M.V. Water and mineral metabolism. In: Nutrition in health and disease. New York: Lippincott, 1976. cap.5, p.47-69.

MOIR, K.W. Determination of oxalic acid in plant the Queensland. Journal of Agriculture Science, v.10, n.1, p.1-3, mar. , 1953.

NATIONAL CENTER FOR HEALTH STATISTICS, 1987. Summary: National Hospital Discharge Survey Advance Data from Vital and Health Statistics, $n^{\circ}$. 159. DHNS Publ. No (PHS) 88-1250. Hyattsville, MD, National Center for Health Statitics, 1988.

PONEROS, A.G.; ERDMAN JÚNIOR, J.W. Biovailability of calcium from tofu, tortillas, nonfat dry milk and mozarella cheese in rats: effect of suplemental ascorbic acid. Journal of Food Science, v.53, n.1, p. 208-210,230, 1988.

PONEROS, A.G.; ERDMAN JÚNIOR, J.W. Biovailability of calcium from sesame seeds, almond powder, whole wheat bred, spinach and nonfat dry milk in rats. Journal of Food Science, v.54, n.1, p. $150-153,1989$ 
SALGADO, J.M.; SANTOS, A.C.; FISCHER, C.A.G. Efeito da suplementação de fontes de minerais sobre a mistura arroz/feijão. Alimentação, n.58, p.32-36, 1982.

SARRUGE, J.R. ; HAAG, H.P. Análises químicas em plantas. Piracicaba: ESALQ/Departamento de Química, 1974. 56p.

SGARBIERI, V.C. Proteínas em alimentos protéicos. Propriedades - degradação - modificações. In:

Propriedades nutricionais das proteínas. São Paulo: Varlea, 1996. cap. 4, p.337-386.

SMITH, I.F. Leafy vegetables as sources of mineral in southern Nigerian diets. Nutritional Reports International, v.26, n.4, p.679-688, 1982.

TURNER, L.W. ; WHITNEY, E.N. Nature vs nature: the calcium controversy. Nutr. Clinical, v.4, n.1, 1989.

VITAKON, P. Oxalate in vegetable amaranth (Amaranthus gangeticus). Forms, contents and their possible implications for human health. Journal Science Agricultural, v.48, p.469-474, 1986. 
WEAVER, C.M. ; MARTIN, B.R. ; EBNER, J.S. ; KRUEGER, C.A. Oxalic acid decreases calcium absorption in rats. The Journal of Nutrition, v. 117, n.11, p.1903-1906, 1987. 